\title{
Depressive Tendency and the Risk of Death from Pneumonia: The JACC Study
}

\author{
Naohito Tanabe ${ }^{1}$, Nao Seki ${ }^{2}$, Chika Horikawa ${ }^{1}$, Hiroshi Yatsuya ${ }^{3}$, Kazumasa Yamagishi ${ }^{4}$, \\ Hiroyasu Iso ${ }^{5}$, Shigekazu Ukawa ${ }^{6}$ and Akiko Tamakoshi ${ }^{7}$; on behalf of JACC Study group
}

\begin{abstract}
:
Objective The burden of death from pneumonia is expected to increase with the aging of the population, as has been observed in Japan. Depressive tendency, a common psychosocial sign, may be a risk factor for pneumonia due to its possible association with some immune dysfunction. This study aimed to clarify the association between depressive tendency and the risk of death from pneumonia.

Methods A population-based cohort that consisted of 75,174 Japanese men and women was followed for a median of 19.1 years. Four psychological and behavioral symptoms (depressive symptoms) were used to evaluate depressive tendency.

Results A total of 1,329 deaths from pneumonia were observed. Depressive symptoms were positively and dose-dependently associated with the risk of death from pneumonia ( $<<0.001$ for trend), and subjects with $\geq 2$ depressive symptoms showed a significantly elevated risk compared to those without any symptoms [multivariable hazard ratio (HR), 1.66; 95\% confidence interval (CI), 1.39-1.99]. This association was not significantly affected by sex or age at baseline. The elevated risk was still significant even when subjects were limited to those without any medical histories. The excess risk was observed not only for death occurring within the first 10 years of follow-up (multivariable HR, 2.05; 95\% CI, 1.51-2.78) but also for that occurring in the longer follow-up period (multivariable HR, 1.48; 95\% CI, 1.18-1.85).

Conclusion Depressive tendency may be a risk factor for death from pneumonia. Further studies using a more reliable tool for the evaluation of depressive state are necessary to confirm this relationship.
\end{abstract}

Key words: depressive tendency, pneumonia, mortality, risk factor, cohort study

(Intern Med 59: 3123-3130, 2020)

(DOI: 10.2169/internalmedicine.5052-20)

\section{Introduction}

Pneumonia is the fifth leading cause of death in Japan: 94,661 Japanese died from pneumonia in 2018 (1). In addition, 38,460 Japanese died from aspiration pneumonia, and 3,325 died from influenza. The mortality rate due to pneumonia increased until 2011 along with the aging of Japanese society (1). After that, however, the mortality rate began to decline gradually. This decrease strangely coincided with the decrease in suicide mortality. There is no evidence linking these trends, but the depressive state of the Japanese population might have affected both mortality rates. Depression, a well-known suicide risk factor (2), is reported to increase susceptibility to infection (3-7).

Physical or behavioral factors, such as underweight $(8,9)$, swallowing problems (9), poor dental hygiene (9), and smoking $(8,9)$, have been considered risk factors for pneu-

${ }^{1}$ Department of Health and Nutrition, Faculty of Human Life Studies, University of Niigata Prefecture, Japan, ${ }^{2}$ School of Health Sciences, Faculty of Medicine, Niigata University, Japan, ${ }^{3}$ Department of Public Health, Fujita Health University School of Medicine, Japan, ${ }^{4}$ Department of Public Health Medicine, Faculty of Medicine, and Health Services Research and Development Center, University of Tsukuba, Japan, ${ }^{5}$ Public Health, Department of Social and Environmental Medicine, Osaka University Graduate School of Medicine, Osaka University, Japan, ${ }^{6}$ Graduate School of Human Life Science, Osaka City University, Japan and ${ }^{7}$ Department of Public Health, Hokkaido University Graduate School of Medicine, Japan

Received: April 8, 2020; Accepted: June 23, 2020; Advance Publication by J-STAGE: August 12, 2020

Correspondence to Dr. Naohito Tanabe, tanabena@gmail.com 
monia. Our previous study found that physical inactivity and blood transfusion were also considered risk factors (8). Dementia has also been associated with an increased risk of pneumonia (10). However, few studies have investigated the risk of pneumonia in relation to psychosocial factors.

Depression is one of the most common psychological disorders. To our knowledge, two cohort studies have evaluated the relationship between the risk of pneumonia and depression. Davydow et al. studied 6,704 Americans $>50$ years old for 6.8 years on average (11). They identified 875 (13.1\%) hospitalized subjects with pneumonia during the follow-up and found that depression at baseline was significantly associated with an elevated odds of hospitalization. Takeida et al. investigated 2,166 Japanese inhabitants 65-74 years old for up to 4.2 years, and 6 deaths from pneumonia was observed (12). A higher score on the Self-rating Depression Scale (13) at baseline was significantly associated with a higher mortality rate due to pneumonia. No large-scale cohort study, however, has investigated the independent relationship between mortality risk of pneumonia and a depressive state considering possible confounding factors. We also do not have enough knowledge concerning the long-term risk of pneumonia associated with depressive tendency.

In the present study, we aimed to clarify the independent relationship between certain psychosocial or behavioral symptoms, which might reflect the depressive tendency, and the risk of mortality due to pneumonia.

\section{Materials and Methods}

\section{Subjects}

This study was conducted under the Japan Collaborative Cohort Study for Evaluation of Cancer Risk sponsored by Monbusho (JACC Study) $(14,15)$. The JACC study is a population-based multicenter cohort study started between 1988 and 1990. We followed 110,585 eligible participants (46,395 men and 64,190 women) 40-79 years old living in 45 communities across Japan. Baseline data were obtained using a self-administered questionnaire regarding their lifestyles and medical histories. Individual informed consent was obtained in writing in 35 of the 45 study areas and verbally from 1 area. In another nine study areas, group consent was given by the head of each local government, which was common in Japan until the Japanese ethical guideline for epidemiological studies was first established in 2002. The study design was approved by the Ethics Board of Hokkaido University School of Medicine and Nagoya University School of Medicine.

Among all eligible participants of the JACC cohort, 25,296 subjects from 13 areas were excluded from the study population because the baseline survey in these areas did not evaluate their 4 psychological or behavioral symptoms used to assess depressive tendency. We further excluded 3,920 subjects due to a lack of a valid response to the question concerning these 4 symptoms. In addition, 6,195 subjects with medical histories of tuberculosis, other chronic respiratory disease or cerebrovascular disease were excluded. Consequently, 75,174 subjects (30,185 men and 44,989 women) were selected for this study. Their mean age at baseline was $57.3 \pm 10.1$ years old.

\section{Baseline assessments}

We assessed the depressive tendency following the procedure established by Tamakoshi et al (16). Four psychological or behavioral items in the baseline questionnaire were used for convenience to assess depressive tendency, as follows: (i) "Do you think your life is meaningful?" (ii) "Do you think you make decisions quickly?" (iii) "Are you enjoying your life?" and (iv) "Do you feel others rely very much on you?" We provided positive, neutral and negative response categories for each question item and considered negative responses to likely reflect depressive symptoms of (i) sense of meaninglessness, (ii) diminished ability to think or concentrate, or indecisiveness (indecisiveness), (iii) diminished interest or pleasure (diminished pleasure) and (iv) feelings of worthlessness. Although we did not evaluate the depressive mode directly, we considered a negative response to item (i), sense of meaninglessness, to somewhat represent emptiness or hopelessness, which is a key symptom of depressive mode. Since depressive mode, indecisiveness, diminished pleasure and feelings of worthlessness are included among the nine major symptoms of a major depressive episode according to the Diagnostic and Statistical Manual of Mental Disorders, 5th edition (DSM-5) (17), we counted negative responses to the question items as the number of depressive symptoms in order to assess the strength of the depressive tendency. The internal consistency expressed as Cronbach's $\alpha$ for the study population was 0.46 .

The body mass index (BMI; calculated using height and weight); smoking habit (current, former, or never); drinking habit (current, former, or never); medical histories (present or absent) of hypertension, myocardial infarction, diabetes mellitus, cancer and blood transfusion; time spent exercising; and time spent walking were evaluated based on the answer to the baseline questionnaire for possible confounding factors. These factors were significantly associated with the risk of death due to pneumonia for either men or women in our previous study (8). The questions for time spent exercising and walking were "How much time do you spend doing sports or exercising every week in average?" and "How much time do you spend walking, indoor or outdoor, every day on average?", respectively. Available choices were " $\geq 5$ h," "3-4 h," "1-2 h" and " $<1$ h" for time spent exercising and " $\geq 1$ h," "30 min-1 h," "30 min" and "<30 min" for time spent walking. The presence of any currently undertreated diseases (present or absent) and the presence of perceived mental stress were also assessed as possible confounding factors in this study. The question for perceived mental stress was "What is the level of stress in your daily life?", and the response categories were "extremely high," "high," "medium" or "low." 


\section{Follow-up}

Death and moving out of the study areas were assessed through resident registration records provided by the local governments of the study areas. Individuals who moved out of a study area were censored for their follow-up. The date and cause of death were confirmed based on the official records of death certificates for vital statistics, with the permission of the Director-General of the Prime Minister's Office (Ministry of Public Management, Home Affairs, Post and Telecommunications) and/or the Ministry of Health, Labour and Welfare in Japan. Based on the direct and indirect causes of death determined by the attending physician for each death, government officials selected and coded a single cause as the underlying cause of death according to the International Classification of Diseases (ICD): the 9th Revision of ICD was in use until 1994, after which the 10th Revision was used. The JACC study group converted ICD-9 codes to ICD-10 codes. In this study, death from pneumonia was confirmed when "influenza and pneumonia" (J10-18) or "pneumonitis due to inhalation of food and vomit" (J69.0), generally called aspiration pneumonia, was coded as the underlying cause of death.

The follow-up was conducted until the end of 2009 in 35 communities, 2008 in 2 communities, 2003 in 4 communities, and 1999 in 4 communities. The median follow-up period for mortality was 19.1 years, and the total follow-up period was 1,218,159 person-years.

\section{Statistical analyses}

The overall statistical differences of baseline characteristics based on the number of depressive symptoms were tested using sex- and age-adjusted multinomial logistic regression analyses. The mean age at death was compared between death from pneumonia and other causes; the difference was tested using Student's $t$-test. Hazard ratios (HRs) and $95 \%$ confidence intervals (CIs) based on the number of depressive symptoms for death from pneumonia were calculated in sex- and age-adjusted and multivariable Cox proportional hazards models. Multivariable models were adjusted for sex; age; body mass index; medical histories of diabetes, hypertension, myocardial infarction, cancer and blood transfusion; presence of any currently undertreated diseases; smoking habit; drinking habits; time spent exercising; time spent walking and perceived mental stress. In these models, age was adjusted for 5-year interval categories, and the BMI was adjusted for the following 4 categories: $<18.5 \mathrm{~kg} / \mathrm{m}^{2}$, $18.5-<23.0 \mathrm{~kg} / \mathrm{m}^{2}, 23.0-<25.0 \mathrm{~kg} / \mathrm{m}^{2}$ and $\geq 25.0 \mathrm{~kg} / \mathrm{m}^{2}$. For every variable, missing values were also treated as a single category to avoid losing a large number of data in multivariable models.

The sex- and age-adjusted and multivariable HRs and CIs based on each depressive symptom were also calculated. Multivariable model 1 was adjusted for the same variables described earlier. Multivariable model 2 was further adjusted for all depressive symptoms. All statistical analyses were performed using the IBM SPSS ver. 21.0 software package (IBM, Armonk, USA).

\section{Results}

Of the 75,174 study subjects, 18,302 (24.3\%) had at least 1 depressive symptom, and 5,328 (7.1\%) had $\geq 2$ depressive symptoms (Table 1). The mean values or frequencies of all variables except for smoking habit were significantly different between groups classified by the number of depressive symptoms. In the group with $\geq 2$ depressive symptoms, mean age was the oldest and the highest frequencies were observed for medical histories of diabetes mellitus, hypertension, myocardial infarction and blood transfusion; any currently treated diseases and high perceived mental stress, whereas in the "none" group, a mean value of body mass index was the highest and the highest frequencies were observed for men, a medical history of cancer, and current drinkers. More depressive symptoms were associated with less time spent exercising and walking.

A total of 16,761 deaths occurred during the follow-up period. Of those deceased subjects, 1,329 died from pneumonia, including 6 deaths from influenza, 35 from bacterial pneumonia, 1,151 from pneumonia due to an unspecified organism and 137 from aspiration pneumonia. The mortality rate from pneumonia was $1.09 / 1000$ person-years. Almost all pneumonia cases $(97.4 \%)$ died after reaching 65 years old, and more than half $(67.0 \%)$ died at $\geq 80$ years old (Table 2). The mean age at death was significantly older in the pneumonia cases $(82.1 \pm 7.7$ years old) than in those with other causes of death $(76.2 \pm 9.9$ years old $)$.

The mortality rate from pneumonia (Table 3) and the risk of death from pneumonia (Table 4) dose-dependently increased with an increasing number of depressive symptoms in both men and women $(\mathrm{p}<0.001$ for trend). Subjects with $\geq 2$ depressive symptoms showed a significantly increased risk of death from pneumonia compared to those without any symptoms (multivariable HR, 1.66; 95\% CI, 1.39-1.99). This positive association was still observed even after excluding aspiration pneumonia from the causes of death due to pneumonia. The positive association between depressive symptoms and the risk of pneumonia death was insignificantly affected by sex (multivariable $\mathrm{p}$ for interaction=0.270) or age at baseline (40-64 vs. 65-79 years) (multivariable $\mathrm{p}$ for interaction=0.734). The elevated risk associated with $\geq 2$ depressive symptoms was still significant even when subjects were limited to those without any medical histories (multivariable HR, 1.59; 95\% CI, 1.20-2.10). Having $\geq 2$ symptoms were positively associated not only with death occurring within the first 10 years of follow-up (multivariable HR, 2.05; 95\% CI, 1.51-2.78) but also with that occurring in the longer follow-up period (multivariable HR, 1.48; $95 \%$ CI, 1.18-1.85). The risk was higher among subjects with a younger age at death than in older subjects; only those who died at $\geq 90$ years old did not show a significantly elevated risk (multivariable HR, 1.07; 95\% CI 0.64-1.79). 
Table 1. Characteristics of Study Subjects according to Score of Depressive Symptoms.

\begin{tabular}{|c|c|c|c|c|}
\hline & \multicolumn{4}{|c|}{ number of depressive symptoms } \\
\hline & $\begin{array}{c}\text { none } \\
(n=56,872)\end{array}$ & $\begin{array}{c}1 \\
(n=12,974)\end{array}$ & $\begin{array}{c}\geq 2 \\
(n=5,328)\end{array}$ & $\mathrm{p}^{*}$ \\
\hline Sex, number of men & $23,679(41.6 \%)$ & $4,773(36.8 \%)$ & $1,733(32.5 \%)$ & $<0.001$ \\
\hline Age (years) & $57.0 \pm 10.0$ & $57.8 \pm 10.3$ & $58.1 \pm 10.7$ & $<0.001$ \\
\hline Body mass index $\left(\mathrm{kg} / \mathrm{m}^{2}\right)$ & $22.9 \pm 3.4$ & $22.8 \pm 3.3$ & $22.7 \pm 5.8$ & $<0.001$ \\
\hline \multicolumn{5}{|l|}{ Medical history } \\
\hline Diabetes mellitus & $2,587(4.5 \%)$ & $584(4.5 \%)$ & $303(5.7 \%)$ & $<0.001$ \\
\hline Hypertension & $11,110(19.5 \%)$ & $2,836(21.9 \%)$ & $1,186(22.3 \%)$ & $<0.001$ \\
\hline Myocardial infarction & $1,427(2.5 \%)$ & $346(2.7 \%)$ & $177(3.3 \%)$ & 0.048 \\
\hline Cancer & $7,078(12.4 \%)$ & $1,340(10.3 \%)$ & $632(11.9 \%)$ & $<0.001$ \\
\hline Blood transfusion & $4,872(8.6 \%)$ & $1,240(9.6 \%)$ & $556(10.4 \%)$ & $<0.001$ \\
\hline Any currently treated diseases & $13,357(23.5 \%)$ & $3,018(23.3 \%)$ & $1,508(28.3 \%)$ & $<0.001$ \\
\hline Drinking habit & & & & $<0.001$ \\
\hline Current & $25,014(44.0 \%)$ & $4,885(37.7 \%)$ & $1,797(33.7 \%)$ & \\
\hline Former & $1,754(3.1 \%)$ & $527(4.1 \%)$ & $236(4.4 \%)$ & \\
\hline Never & $26,736(47.0 \%)$ & $6,690(51.6 \%)$ & $2,921(54.8 \%)$ & \\
\hline Missing & $3,368(5.9 \%)$ & $872(6.7 \%)$ & $374(7.0 \%)$ & \\
\hline Smoking habit & & & & 0.305 \\
\hline Current & $13,880(24.4 \%)$ & $2,771(21.4 \%)$ & $1,044(19.6 \%)$ & \\
\hline Former & $6,071(10.7 \%)$ & $1,292(10.0 \%)$ & $451(8.5 \%)$ & \\
\hline Never & $31,986(56.2 \%)$ & $7,685(59.2 \%)$ & $3,278(61.5 \%)$ & \\
\hline Missing & 4,935 (8.7\%) & $1,226(9.4 \%)$ & $555(10.4 \%)$ & \\
\hline Time spent exercising (per week) & & & & $<0.001$ \\
\hline $5 \mathrm{~h}$ or more & $3,283(5.8 \%)$ & $497(3.8 \%)$ & $170(3.2 \%)$ & \\
\hline $3-4 \mathrm{~h}$ & $3,588(6.3 \%)$ & $591(4.6 \%)$ & $169(3.2 \%)$ & \\
\hline $1-2 \mathrm{~h}$ & $8,834(15.5 \%)$ & $1,375(10.6 \%)$ & $398(7.5 \%)$ & \\
\hline$<1 \mathrm{~h}$ & $37,699(66.3 \%)$ & $9,726(75.0 \%)$ & $4,289(80.5 \%)$ & \\
\hline Missing & $3,468(6.1 \%)$ & $785(6.1 \%)$ & $302(5.7 \%)$ & \\
\hline Time spent walking (per day) & & & & $<0.001$ \\
\hline $1 \mathrm{~h}$ or more & $26,990(47.5 \%)$ & $5,327(41.1 \%)$ & $2,147(40.3 \%)$ & \\
\hline $30 \mathrm{~min}-1 \mathrm{~h}$ & $10,813(19.0 \%)$ & $2,135(16.5 \%)$ & $882(16.6 \%)$ & \\
\hline around $30 \mathrm{~min}$ & $9,297(16.3 \%)$ & $1,883(14.5 \%)$ & $916(17.2 \%)$ & \\
\hline$<30 \mathrm{~min}$ & $5,159(9.1 \%)$ & $1,427(11.0 \%)$ & $820(15.4 \%)$ & \\
\hline Missing & $4,613(8.1 \%)$ & $2,202(17.0 \%)$ & $563(10.6 \%)$ & \\
\hline Perceived mental stress & & & & $<0.001$ \\
\hline Medium or low & $44,378(78.0 \%)$ & $9,259(71.4 \%)$ & $3,156(59.2 \%)$ & \\
\hline High & $10,286(18.1 \%)$ & $3,052(23.5 \%)$ & $1,867(35.0 \%)$ & \\
\hline Missing & $2,208(3.9 \%)$ & $663(5.1 \%)$ & $305(5.7 \%)$ & \\
\hline
\end{tabular}

When individual depressive symptoms were analyzed, every symptom was significantly associated with the risk of death from pneumonia in sex- and age-adjusted models (Table 5). When all possible confounding factors and other depressive symptoms were adjusted simultaneously in multivariable model 2, "diminished pleasure" and "feelings of worthlessness" were not associated with risk of death from pneumonia. "Sense of meaninglessness" showed the strongest risk in every model, followed by "indecisiveness" (HR, 1.46; 95\% CI, 1.22-1.75; and HR, 1.28; 95\% CI, 1.09-1.49, respectively, in multivariable model 2).

\section{Discussion}

In this large-scale cohort study, the number of depressive symptoms and elevated risk of death from pneumonia were positively and dose-dependently associated. Having $\geq 2$ depressive symptoms was significantly associated with an elevated risk, irrespective of sex and age at baseline. The positive association between depressive symptoms and the risk of death from pneumonia remained statistically significant even after excluding subjects with some medical histories or with a relatively short observation period ( $<10$ years).

The elevated risk associated with depressive symptoms seemed to be higher for deaths in younger subjects than in older ones. This may be because the contribution of other risk factors for pneumonia, such as underweight $(8,9)$, swallowing problems (9), and dementia (10), can increase with aging, which would reduce the relationship between depressive tendency and the risk of death from pneumonia 
in older individuals.

Regarding other infectious diseases, a depressive state or mood disorder has been positively associated with the risk of common colds in prospective (3) as well as retrospective $(4,5)$ observational studies, and the 3 -year risk of death from influenza was evaluated in a cohort study (6), while the risk of periodontitis was examined in a case-control study (7). Therefore, depressed subjects might have increased susceptibility to infection. The clinical outcomes of a disease also affect the mortality. From this perspective, two studies investigating the clinical outcomes of patients with pneumonia were found. Kao et al. reported that patients with pneumonia and depressive disorder had a significantly higher probability of in-hospital death than those without depressive disorder (18). Mather et al. reported that a history of anxiety or depression was associated with a

Table 2. Distribution of Age at Death.

\begin{tabular}{ccc}
\hline $\begin{array}{c}\text { Age } \\
\text { (years })\end{array}$ & $\begin{array}{c}\text { Pneumonia } \\
(\mathrm{n}=1,329)\end{array}$ & $\begin{array}{c}\text { Other causes } \\
(\mathrm{n}=15,412)\end{array}$ \\
\hline $40-44$ & $1(0.1)$ & $27(0.2)$ \\
$45-49$ & $1(0.1)$ & $89(0.6)$ \\
$50-54$ & $3(0.2)$ & $276(1.8)$ \\
$55-59$ & $10(0.8)$ & $527(3.4)$ \\
$60-64$ & $20(1.5)$ & $1,110(7.2)$ \\
$65-69$ & $54(4.1)$ & $1,702(11.0)$ \\
$70-74$ & $109(8.2)$ & $2,356(15.3)$ \\
$75-79$ & $240(18.1)$ & $3,093(20.1)$ \\
$80-84$ & $345(26.0)$ & $3,077(20.0)$ \\
$85-89$ & $344(25.9)$ & $2,005(13.0)$ \\
$90-94$ & $161(12.1)$ & $969(6.3)$ \\
$95-99$ & $41(3.1)$ & $179(1.2)$ \\
$100-104$ & $0(0.0)$ & $2(0.0)$ \\
average & $82.1 \pm 7.7$ & $76.2 \pm 9.9$ \\
& & $\mathrm{p}<0.001$ \\
\hline
\end{tabular}

Data are $\mathrm{n}(\%)$ or mean $\pm \mathrm{SD}$.

ICD10 codes for pneumonia, J10-18 or J69.0. 1.62-fold increased odds of 30-day all-cause readmission after discharge from the index pneumonia admission (19).

Immunological mechanisms have been proposed to explain the increased susceptibility to infectious diseases and poor clinical outcomes in depressive patients. Elevated levels of circulating pro-inflammatory cytokines, such as interleukin 6 (IL-6) $(20,21)$ and tumor necrosis factor- $\alpha$ (TNF$\alpha)(21)$, have been observed in patients with depression. Yende et al. reported that higher levels of circulating IL-6 and TNF in well-functioning elderly individuals were associated with an increased risk of subsequent hospitalization due to pneumonia (22). Depression was also associated with cellular immune suppression $(21,23)$. Such an imbalance in the immune function may be a possible mechanism linking a depressive tendency and the risk of death from pneumonia.

Nonadherent behaviors may cause a delay in starting medication for pneumonia, which can lead to poor outcomes. A meta-analysis of 12 studies revealed that depression was significantly associated with a risk of noncompliance with medical treatment recommendations (24). A cohort study in the Netherlands also reported that depression is a risk factor for medication nonadherence (25).

The strengths of this study include the large sample size and long follow-up period. These characteristics allowed us to include many confounding factors in the multivariable analyses and to perform some stratified and sensitivity analyses. Consequently, the following two important findings were confirmed: 1) a positive and independent association between depressive tendency and the risk of death from pneumonia was evident even after excluding subjects with a medical history, and 2) depressive tendency can affect not only the short-term but also the long-term risk of death from pneumonia. These findings strongly suggest that the effect of depressive tendency on death due to pneumonia is not related to the presence of comorbidities that can cause depressive tendency.

Table 3. Overall and Sex-specific Statistics of Mortality from Pneumonia According to Number of Depressive Symptoms.

\begin{tabular}{lccc}
\hline & \multicolumn{3}{c}{ number of depressive symptoms } \\
\cline { 2 - 4 } & none & 1 & $\geq 2$ \\
\hline Overall & $(\mathrm{n}=56,872)$ & $(\mathrm{n}=12,974)$ & $(\mathrm{n}=5,328)$ \\
Person-years & 928,063 & 208,282 & 81,814 \\
No of death & 910 & 272 & 147 \\
Death rate $(/ 1,000$ person-years $)$ & 0.98 & 1.31 & 1.80 \\
Men & $(\mathrm{n}=23,679)$ & $(\mathrm{n}=4,773)$ & $(\mathrm{n}=1,733)$ \\
Person-years & 379,805 & 73,989 & 25,645 \\
No of death & 569 & 157 & 79 \\
Death rate $(/ 1,000$ person-years $)$ & 1.50 & 2.12 & 3.08 \\
Women & $(\mathrm{n}=33,193)$ & $(\mathrm{n}=8,201)$ & $(\mathrm{n}=3,595)$ \\
Person-years & 548,258 & 134,294 & 56,168 \\
No of death & 341 & 115 & 68 \\
Death rate $(/ 1,000$ person-years $)$ & 0.62 & 0.86 & 1.21 \\
\hline
\end{tabular}

$\mathrm{n}$ : number of subjects at risk 
Table 4. Hazard Ratios and $95 \%$ CIs of Mortality from Pneumonia According to Number of Depressive Symptoms.

\begin{tabular}{|c|c|c|c|c|c|c|c|c|c|c|c|c|}
\hline & \multicolumn{12}{|c|}{ number of depressive symptoms } \\
\hline & none & & 1 & & $\geq 2$ & \multirow{3}{*}{$\begin{array}{l}\mathrm{p} \text { for } \\
\text { trend }\end{array}$} & none & & 1 & & $\geq 2$ & \multirow{3}{*}{$\begin{array}{l}\mathrm{p} \text { for } \\
\text { trend }\end{array}$} \\
\hline & \multicolumn{3}{|c|}{ Sex- and age-adjusted } & \multirow[b]{2}{*}{ HR } & \multirow[b]{2}{*}{$(95 \% \mathrm{CI})$} & & \multicolumn{3}{|c|}{ Multivariable } & \multirow[b]{2}{*}{ HR } & \multirow[b]{2}{*}{$(95 \% \mathrm{CI})$} & \\
\hline & HR & $\mathrm{HR}$ & $(95 \% \mathrm{CI})$ & & & & HR & HR & $(95 \% \mathrm{CI})$ & & & \\
\hline Overall & 1.00 & 1.27 & $(1.10-1.46)$ & 1.93 & $(1.62-2.30)$ & $<0.001$ & 1.00 & 1.21 & $(1.06-1.39)$ & 1.66 & $(1.39-1.99)$ & $<0.001$ \\
\hline Non-aspiration pneumonia* & 1.00 & 1.26 & $(1.09-1.46)$ & 2.00 & $(1.66-2.40)$ & $<0.001$ & 1.00 & 1.21 & $(1.04-1.40)$ & 1.73 & $(1.43-2.08)$ & $<0.001$ \\
\hline Men & 1.00 & 1.31 & $(1.09-1.56)$ & 2.25 & $(1.78-2.86)$ & $<0.001$ & 1.00 & 1.24 & $(1.04-1.49)$ & 1.90 & $(1.49-2.43)$ & $<0.001$ \\
\hline Women & 1.00 & 1.23 & $(0.99-1.52)$ & 1.60 & $(1.23-2.09)$ & $<0.001$ & 1.00 & 1.16 & $(0.93-1.44)$ & 1.39 & $(1.06-1.82)$ & 0.002 \\
\hline Stratified by age at baseline & \multicolumn{3}{|c|}{$(\mathrm{p}$ for interaction $=0.718)$} & & & & \multicolumn{3}{|c|}{$(\mathrm{p}$ for interaction $=0.734)$} & & & \\
\hline 40-64 years & 1.00 & 1.36 & $(1.04-1.78)$ & 1.93 & $(1.35-2.74)$ & $<0.001$ & 1.00 & 1.29 & $(0.99-1.69)$ & 1.75 & $(1.22-2.51)$ & $<0.001$ \\
\hline $65-74$ years & 1.00 & 1.22 & $(1.04-1.44)$ & 1.91 & $(1.56-2.35)$ & $<0.001$ & 1.00 & 1.16 & $(0.99-1.36)$ & 1.60 & $(1.30-1.98)$ & $<0.001$ \\
\hline \multicolumn{13}{|l|}{ Sensitivity analyses } \\
\hline \multicolumn{13}{|l|}{ Length of follow-up } \\
\hline Limitted to 10 years & 1.00 & 1.58 & $(1.23-2.02)$ & 2.64 & $(1.97-3.55)$ & $<0.001$ & 1.00 & 1.44 & $(1.12-1.85)$ & 2.05 & $(1.51-2.78)$ & $<0.001$ \\
\hline$\geq 10$ years & 1.00 & 1.16 & $(0.98-1.37)$ & 1.66 & $(1.33-2.07)$ & $<0.001$ & 1.00 & 1.12 & $(0.95-1.33)$ & 1.48 & $(1.18-1.85)$ & 0.001 \\
\hline \multicolumn{13}{|l|}{ Age of death } \\
\hline$<80$ years old $\ddagger$ & 1.00 & 1.27 & $(0.99-1.62)$ & 2.36 & $(1.77-3.14)$ & $<0.001$ & 1.00 & 1.18 & $(0.92-1.51)$ & 2.01 & $(1.50-2.70)$ & $<0.001$ \\
\hline $80-89$ years old $\$$ & 1.00 & 1.34 & $(1.12-1.62)$ & 1.87 & $(1.45-2.41)$ & $<0.001$ & 1.00 & 1.29 & $(1.07-1.56)$ & 1.60 & $(1.23-2.07)$ & $<0.001$ \\
\hline$\geq 90$ years old $\$$ & 1.00 & 0.98 & $(0.67-1.43)$ & 1.30 & $(0.80-2.12)$ & 0.256 & 1.00 & 0.89 & $(0.61-1.31)$ & 1.07 & $(0.64-1.79)$ & 0.701 \\
\hline
\end{tabular}

Multivariable model adjusted for sex, age, body mass index, histories of diabetes, hypertension, myocardial infarction, cancer and blood transfusion, presence of any currently undertreated diseases, smoking and drinking habits, time spent exercising, time spent walking, and perceived mental stress.

*Pneumonitis due to inhalation of food and vomit (C69.0) was classified as non-pneumonia death.

${ }^{\dagger}$ Subjects were those who had neither medical histories listed in Table 1 nor any diseases treated at baseline.

${ }^{\ddagger}$ Follow-up was censored at the previous month to the birth month of 80 years old.

${ }^{\S}$ Subjects were those who were alive at the birth month of 80 years old and follow-up for them was censored at the previous month to the birth month of 90 years old.

\$Subjects were those who were alive at the birth month of 90 years old.

HR: hazard ratio, CI: confidence interval

Table 5. Prevalence of Each Depressive Symptom at Baseline and Its Hazard Ratios and 95\% CIs of Mortality from Pneumonia.

\begin{tabular}{|c|c|c|c|c|c|c|c|c|}
\hline & \multirow{2}{*}{\multicolumn{2}{|c|}{ Prevalence* }} & \multirow{2}{*}{\multicolumn{2}{|c|}{$\begin{array}{c}\text { Sex- and } \\
\text { age-adjusted }\end{array}$}} & \multicolumn{4}{|c|}{ Multivariable } \\
\hline & & & & & \multicolumn{2}{|c|}{ model 1} & \multicolumn{2}{|c|}{ model 2} \\
\hline & $\mathrm{n}$ & $(\%)$ & HR & $(95 \% \mathrm{CI})$ & HR & $(95 \% \mathrm{CI})$ & HR & $(95 \% \mathrm{CI})$ \\
\hline Sense of meaninglessness & 6,095 & $(8.1 \%)$ & 1.78 & $(1.50-2.11)$ & 1.57 & $(1.33-1.87)$ & 1.46 & $(1.22-1.75)$ \\
\hline Indecisiveness & 7,858 & $(10.5 \%)$ & 1.52 & $(1.31-1.76)$ & 1.40 & $(1.21-1.63)$ & 1.28 & $(1.09-1.49)$ \\
\hline Diminished pleasure & 2,929 & $(3.9 \%)$ & 1.44 & $(1.07-1.94)$ & 1.23 & $(0.90-1.67)$ & 0.92 & $(0.67-1.27)$ \\
\hline Feelings of worthlessness & 8,494 & $(11.3 \%)$ & 1.42 & $(1.22-1.65)$ & 1.31 & $(1.12-1.53)$ & 1.18 & $(1.00-1.38)$ \\
\hline
\end{tabular}

*Prevalence among 75,174 study subjects.

model 1 , adjusted for same variables described in the footnotes to Table 4.

model 2, further adjusted for all components in the table each other.

However, there are strong limitations associated with this study assessing depressive tendency. The baseline questionnaire itself was not designed to evaluate the depressive tendency when our cohort study was organized. In addition, the Cronbach's $\alpha$ for our counting system of depressive symptoms was relatively low. Therefore, our results cannot conclude a positive association between "depression" and the risk of death from pneumonia. Nevertheless, we believe that the number of depressive symptoms can, to some extent, re- flect depressive tendency, as these symptoms can represent certain key symptoms of major depressive disorder, as noted in the Methods section. These limitations should be addressed in future studies.

\section{Conclusion}

Depressive tendency may be an independent risk factor for death due to pneumonia. Further studies using a more 
reliable tool to evaluate the depressive state will be necessary to confirm this relationship.

\section{Study Investigators}

Present members of the JACC Study Group who coauthored this paper are the following: Dr. Akiko Tamakoshi (present chairperson of the study group), Hokkaido University Graduate School of Medicine; Dr. Mitsuru Mori, Hokkaido Chitose College of Rehabilitation; Dr. Yoshihiro Kaneko, Japan Support Center for Suicide Countermeasures; Dr. Ichiro Tsuji, Tohoku University Graduate School of Medicine; Dr. Yosikazu Nakamura, Jichi Medical School; Dr. Hiroyasu Iso, Osaka University School of Medicine; Dr, Kazumasa Yamagishi, Faculty of Medicine, University of Tsukuba; Dr. Haruo Mikami, Chiba Cancer Center; Dr. Michiko Kurosawa, Juntendo University School of Medicine; Dr. Yoshiharu Hoshiyama, Yokohama Soei University; Dr. Naohito Tanabe, University of Niigata Prefecture; Dr. Koji Tamakoshi, Nagoya University Graduate School of Health Science; Dr. Kenji Wakai, Nagoya University Graduate School of Medicine; Dr. Masahiko Ando, Nagoya University Hospital; Dr. Koji Suzuki, Fujita Health University School of Health Sciences; Drs. Shuji Hashimoto \& Hiroshi Yatsuya, Fujita Health University School of Medicine; Dr. Shogo Kikuchi, Aichi Medical University School of Medicine; Dr. Yasuhiko Wada, Wakayama Prefecture Tanabe Public Health Center; Dr. Takashi Kawamura, Kyoto University Health Service; Dr. Yoshiyuki Watanabe, Kyoto Prefectural University of Medicine Graduate.

\section{The authors state that they have no Conflict of Interest (COI).}

\section{Financial Support}

This work was supported by Grants-in-Aid for Scientific Research from the Ministry of Education, Culture, Sports, Science and Technology of Japan (MEXT) (MonbuKagaku-sho); Grantsin-Aid for Scientific Research on Priority Areas of Cancer; and Grants-in-Aid for Scientific Research on Priority Areas of Cancer Epidemiology from MEXT (MonbuKagaku-sho) (Nos. 61010076, 62010074, 63010074, 1010068, 2151065, 3151064, 4151063, 5151069, 6279102, 11181101, 17015022, 18014011, 20014026, 20390156, and 26293138), by Japan Society for the Promotion of Science (JSPS) KAKENHI Grant Number JP 16H 06277, and by Grant-in-Aid from the Ministry of Health, Labour and Welfare, Health and Labour Sciences research grants, Japan (Research on Health Services: H17-Kenkou-007; Comprehensive Research on Cardiovascular Disease and Life-Related Disease: $\mathrm{H}$ 18-Junkankitou [Seishuu]-Ippan-012; Comprehensive Research on Cardiovascular Disease and Life-Related Disease: H19Junkankitou [Seishuu]-Ippan-012; Comprehensive Research on Cardiovascular and Life-Style Related Diseases: H20-Junkankitou [Seishuu]-Ippan-013; Comprehensive Research on Cardiovascular and Life-Style Related Diseases: H23-Junkankitou [Seishuu]Ippan-005); an Intramural Research Fund (22-4-5) for Cardiovascular Diseases of National Cerebral and Cardiovascular Center; Comprehensive Research on Cardiovascular and Life-Style Related Diseases (H26-Junkankitou [Seisaku]-Ippan-001) and H29Junkankitou [Seishuu]-Ippan-003).

\section{Acknowledgement}

We would like to express our sincere appreciation to all staff members involved in this study for their valuable efforts in conducting the baseline survey and the follow-up.

\section{References}

1. Ministry of Health, Labour and Welfare. Vital Statistics in Japan. (in Japanese) [Internet]. [cited 2020 May 25]. Available from: http s://www.mhlw.go.jp/toukei/list/81-1a.html

2. Hirokawa S, Kawakami N, Matsumoto T, et al. Mental disorders and suicide in Japan: a nation-wide psychological autopsy casecontrol study. J Affect Disord 140: 168-175, 2012.

3. Kim HC, Park SG, Leem JH, Jung DY, Hwang SH. Depressive symptoms as a risk factor for the common cold among employees: a 4-month follow-up study. J Psychosom Res 71: 194-196, 2011.

4. Adam Y, Meinlschmidt G, Lieb R. Associations between mental disorders and the common cold in adults a population-based crosssectional study. J Psychosom Res 74: 69-73, 2013.

5. Shinkawa M, Yanai M, Yamaya M, Matsui T, Sasaki H. Depressive state and common cold. Lancet 356: 942, 2000.

6. Zivin K, Yosef M, Miller EM, et al. Associations between depression and all-cause and cause-specific risk of death: a retrospective cohort study in the Veterans Health Administration. J Psychosom Res 78: 324-331, 2015.

7. Sundararajan S, Muthukumar S, Rao SR. Relationship between depression and chronic periodontitis. J Indian Soc Periodontol 19: 294-296, 2015.

8. Inoue Y, Koizumi A, Wada Y, et al. Risk and protective factors related to mortality from pneumonia among middleaged and elderly community residents: the JACC Study. J Epidemiol 17: 194-202, 2007.

9. Torres A, Peetermans WE, Viegi G, Blasi F. Risk factors for community-acquired pneumonia in adults in Europe: a literature review. Thorax 68: 1057-1065, 2013.

10. Foley NC, Affoo RH, Martin RE. A systematic review and metaanalysis examining pneumonia-associated mortality in dementia. Dement Geriatr Cogn Disord 39: 52-67, 2015.

11. Davydow DS, Hough CL, Zivin K, Langa KM, Katon WJ. Depression and risk of hospitalization for pneumonia in a cohort study of older Americans. J Psychosom Res 77: 528-534, 2014.

12. Takeida K, Nishi M, Miyake H. Mental depression and death in elderly persons. J Epidemiol 7: 210-213, 1997.

13. Zung WW, Richards CB, Short MJ. Self-rating depression scale in an outpatient clinic. Further validation of the SDS. Arch Gen Psychiatry 13: 508-515, 1965.

14. Tamakoshi A. Overview of the Japan Collaborative Cohort Study for Evaluation of Cancer (JACC). Asian Pac J Cancer Prev 8 (Suppl): 1-8, 2007.

15. Tamakoshi A, Ozasa K, Fujino Y, et al. Cohort profile of the Japan Collaborative Cohort Study at final follow-up. J Epidemiol 23: 227-232, 2013.

16. Tamakoshi A, Ohno Y. Self-reported sleep duration as a predictor of all-cause mortality: results from the JACC study, Japan. Sleep 27: 51-54, 2004.

17. Depressive disorders. In: Diagnostic and Statistical Manual of Mental Disorders. 5th ed. American Psychiatric Association, Ed. American Psychiatric Publishing, Arlington, VA, 2013: 155-188.

18. Kao LT, Liu SP, Lin HC, Lee HC, Tsai MC, Chung SD. Poor clinical outcomes among pneumonia patients with depressive disorder. PLoS One 9: e116436, 2014.

19. Mather JF, Fortunato GJ, Ash JL, Davis MJ, Kumar A. Prediction of pneumonia 30-day readmissions: a single-center attempt to increase model performance. Respir Care 59: 199-208, 2014.

20. Kiecolt-Glaser JK, Glaser R. Depression and immune function: central pathways to morbidity and mortality. J Psychosom Res 53: 
873-876, 2002.

21. Blume J, Douglas SD, Evans DL. Immune suppression and immune activation in depression. Brain Behav Immun 25: 221-229, 2011.

22. Yende S, Tuomanen EI, Wunderink R, et al. Preinfection systemic inflammatory markers and risk of hospitalization due to pneumonia. Am J Respir Crit Care Med 172: 1440-1446, 2005.

23. Irwin M, Patterson T, Smith TL, et al. Reduction of immune function in life stress and depression. Biol Psychiatry 27: 22-30, 1990.

24. DiMatteo MR, Lepper HS, Croghan TW. Depression is a risk factor for noncompliance with medical treatment: meta-analysis of the effects of anxiety and depression on patient adherence. Arch
Intern Med 160: 2101-2107, 2000.

25. Bet PM, Penninx BW, van Laer SD, Hoogendijk WJ, Hugtenburg JG. Current and remitted depression and anxiety disorders as risk factors for medication nonadherence. J Clin Psychiatry 76: e11141121, 2015.

The Internal Medicine is an Open Access journal distributed under the Creative Commons Attribution-NonCommercial-NoDerivatives 4.0 International License. To view the details of this license, please visit (https://creativecommons.org/licenses/ by-nc-nd/4.0/).

(C) 2020 The Japanese Society of Internal Medicine Intern Med 59: 3123-3130, 2020 